\title{
GODORT Midwinter Update
}

\author{
GODORT Awards Committee \\ 2019 GODORT Award Recipients \\ ProQuest/GODORT/ALA "Documents \\ to the People" Award \\ Laura Harper
}

Newsbank/Readex/GODORT/ALA Catharine J. Reynolds Research Grant Hayley Johnson

Bernadine Abbott Hoduski Founders Award

Kris Kasianovitz

W. David Rozkuszka Scholarships

Ben Chiewphasa

Lauren Hall

Margaret T. Lane/Virginia F. Saunders Memorial Research Award

Authors of Government Information Essentials, edited by Susanne Caro: Jane Canfield, Susanne Caro, David Dillard, Latanya N. Jenkins, Hayley Johnson, Valery King, Shari Laster, Andrew Lopez, Lori Looney, Vickie Mix, Lisa Pritchard, Aimee Quinn, Antoinette Satterfield, Julia Stewart, and Jill Vassilakos-Long

Larry Romans Mentorship Award July Siebecker

GODORT Emerging Leader

Azalea Janel Ebbay

\section{GODORT Education Committee}

The GODORT Education Committee met in person on January 26, 2018. Members and guests received an update on the Government Information Online (GIO) service, which handled 232 questions in calendar year 2018 after moving to the GODORT LibAnswers platform in
May 2018 (https://godort.libguides.com /GIO). About two-thirds of the questions are entered by GPO staff, and the remainder are entered directly by patrons. Sixteen librarians currently volunteer to answer questions.

The four members of the Emerging Leaders team working on GODORT's Emerging Leaders project, Librarian's Election Reference Toolkit, were in attendance: Azalea Ebbay (San Diego Public Library), who is GODORT's sponsored Emerging Leader; Shelley Guerrero, Toledo Public Library; Megan Hamlin-Black, Rhode Island State Library; Leslie Purdie, Folsom Prison. Committee members Gwen Sinclair and Rachel Dobkin met with the team and will serve as Member Guides for the project, which is to create a marketing, implementation, and continuity plan for the toolkit. A prototype of the toolkit is available at https://godort.lib guides.com/voting. The team will present the final project as a poster at the 2019 ALA Annual Conference.

The group discussed surveying LIS programs to learn about how government information is taught so that we can learn about needs and attitudes toward teaching government information. In addition, possible ways to extend government information education beyond LIS programs were discussed, such as a certification program, hosting a continuing education site on LibGuides, and coordinating with Chief Officers of State Library Agencies (COSLA)'s continuing education efforts.

\section{GODORT Publications Committee}

The Committee discussed the possibility of $D t t P$ having a peer-reviewed section/ option that would be discussed in more detail at a later meeting.

The embargo on $D t t P$ was discussed as several columnists wish their columns to be open access immediately, and the problem that authors from the student issue could not access their own articles. The issue was brought to Steering and they were favorable to the idea of ending the embargo. This was put to a vote in the Committee and it passed unanimously. Starting with issue 47:1 DttP will be completely open access.

\section{Notable Documents Update}

The Notable Documents Panel has four new members:

- Richard Mikulski, Portland State University_federal documents selector

- Laura Sare, Texas A\&M Universityinternational documents judge

- Esther Fatuyi, Morgan State University—state and local documents selector

- Bryan Fuller, Morgan State University-panel chair

The following members are continuing on the Panel:

- Suzanne Reinman who was federal documents selector and an international judge, will continue as a federal documents judge

- Christine Adams will continue as a judge for federal documents

- Aimée C. Quinn and Melanie Sims are continuing as judges for state and local documents

- Annelise Sklar will continue as an international documents judge 
- Sonnet Ireland, who was an international documents judge, continues as the international documents selector

The Panel received seventy-four responses from twenty-four people

- thirty-three nominations for Federal Documents

- twenty-eight nominations for State and Local Documents

- thirteen nominations for International Documents

Goals for next year:

- Relocate nomination form to the ALA website

- Highlight international documents from or about Africa and Asia

\section{GODORT Membership Update}

Following a brief message from one of the candidates for ALA president, Councilor Bill Sudduth asked for GODORT to support in principle a Committee on Legislation resolution to acknowledge those who worked to make CRS reports available to the public. This was unanimously approved. He also provided an update on Council activities, including the passage of a resolution to add sustainability as a core value of librarianship and ongoing discussions regarding eliminating library fines and meeting room interpretations.

Treasurer Rebecca Hyde proposed a new budget for the coming fiscal year based on slight decrease in estimates to production costs to DttP. All voted in favor, with one abstention.

Gwen Sinclair, Chair of Education, provided an update on the Emerging Leaders project to create a librarian-tolibrarian toolkit for election reference.
Chair Hallie Pritchett provided an update on the new GODORT website, which is almost complete. Steering will discuss how the website will be maintained in the future.

Past-Chair Shari Laster gave an update about GODORT program proposals for Annual. The juried program "Counting on trust, trusting the count: Census 2020" was accepted and will be held on June 23, 2019, at 9 a.m. GODORT's program will be on the PEGI project and analyzing the results from the 2018 progress report. ChairElect Susanne Caro stated that the two programs GODORT co-sponsored were accepted. "The Data of D.C.: Open Sources for Business Research" will take place on June 23, 2019 at 4 p.m. The allday pre-conference "Guardians of the (Financial) Galaxy: Financial Regulations Generating Free Data, Tools, and Information Along the Way" will be held June 21, 2019.

Past-Chair Shari Laster provided an update on the Ad Hoc Committee on Equity, Diversity, and Inclusion. An interim report has been presented to Steering and the report will be sent to membership at large after Steering has had a chance to discuss it.

Simon Healey, acting as proxy for the chair of the Cataloging Committee stated that the Cataloging Committee has been working on three cataloging toolkits and they have made great progress on the federal toolkit, which will be added to the website in February. The committee would appreciate feedback and suggestions to improve these toolkits.

GODORT Chair Hallie Pritchett led discussion about ALA's upcoming changes to the Midwinter Meeting and how this will affect GODORT.-Julia Frankosky, GODORT Secretary

\section{GODORT Steering Committee}

During the course of the meeting, Steering unanimously voted to approve the award winners as communicated by the Awards Committee chair, Emily Rogers. Steering also unanimously voted to approve the proposed budget presented by Treasurer Rebecca Hyde. The ALA Executive Board Liaison Andrew Pace gave a report.

Chair Hallie Pritchett stated that the new GODORT website is almost done but that Steering will need to determine how best to manage the content on the new site, as well as GODORT's online presence as a whole. Hallie proposed creating a new committee, chaired by the Web Master position currently in the Bylaws, and made up of two or three other people on a rotating basis. This committee would not be responsible for creating content, but would solicit content from the various committees and ensure content is added in a timely manner. They would also be responsible for managing permissions to post on behalf of GODORT. Hallie will draft a proposal for this committee and distribute to Steering for additional discussion.

Chair Hallie Pritchett provided an update regarding GODORT's loss of their dedicated Councilor due to individual membership numbers falling below 1 percent of ALA's membership. Strategies for increasing outreach and engagement of both our current members and prospective members were discussed.

Past-Chair Shari Laster submitted a draft report to Steering with recommendations from the Ad Hoc Committee on Equity, Diversity, and Inclusion. This report will be sent to GODORT membership for feedback.

Awards Committee Chair Emily Rogers requested Steering vote to approve additional funding for two 2019 
Rozkuska Scholarship recipients. Steering unanimously voted to approve the increase in funding.

Past-Chair Shari Laster provided an update on the 2019 Annual Schedule.

Chair of Publications Laura Sare stated that the Publications Committee will be voting to consider ending the DttP embargo and making DttP issues open access immediately upon publication.

International Documents Task Force chair Jim Church will submit a proposal to Steering asking that they endorse an IFLA statement supporting open access and international government information.

Chair Hallie Pritchett will send a proposal to Steering to vote on changing our remaining "Task Forces" (State and Local Documents and International Documents) to "Interest Groups."Julia Frankosky, GODORT Secretary

\section{GODORT Election Results}

The results of the 2019 ALA elections are in!

The following people have been elected to leadership positions in GODORT:

Assistant Chair/Chair-elect: Lynda Kellam

Treasurer: Rebecca C. Hyde

Secretary: Emily Alford

Publications Committee Chair-elect: Michael L. Smith

All terms will start at the end of the ALA Annual Conference in June.

Congratulations to all! 